\title{
A meta-analysis of the association between IL28B polymorphisms and infection susceptibility of hepatitis B virus in Asian population
}

\author{
Jing Chen, Wei Wang, Xiaoguang Li and Jie Xu
}

\begin{abstract}
Background: Several association studies with small sample sizes of two SNPs in IL28BB (rs12979860 and rs8099917) showed inconsistent results, so in this study, we aim to evaluate the association between the two SNPs and infection susceptibility of Hepatitis B Virus (HBV) in Asian population, especially in Chinese population by meta-analysis.

Methods: Search the relevant published papers and perform meta-analysis respectively on IL28B (rs12979860 and rs8099917) in Asian population and Chinese population under an additive genetic model by STATA11.0.

Results: The pooled odds ratios (OR) of rs 12979860 are $0.79\left(95 \% \mathrm{Cl}, 0.53-1.18 ; \mathrm{P}=0.25, \mathrm{I}^{2}=63.2 \%\right)$ and $1.62(95 \% \mathrm{Cl}$, 1.04-2.51; $P=0.033, I^{2}=54.3 \%$ ) respectively in Asian population and Chinese population analysis. The pooled OR of rs8099917 are $1.05\left(95 \% \mathrm{Cl}, 0.93-1.19 ; \mathrm{P}=0.44, \mathrm{I}^{2}=43.3 \%\right)$ and $0.97\left(95 \% \mathrm{Cl}, 0.84-1.23 ; \mathrm{P}=0.726, \mathrm{I}^{2}=15.6 \%\right)$ respectively in Asian population and Chinese population analysis.

Conclusion: Our study demonstrated that T allele of rs12979680 can increase the risk of HBV infection in Chinese population but not Asian population under an additive genetic model. There is no association between rs8099917 and HBV infection in Chinese population and Asian population.
\end{abstract}

Keywords: Meta-analysis, IL28B, rs12979680, rs8099917, HBV, Infection susceptibility

\section{Background}

Hepatitis B virus (HBV) is a worldwide health problem, and it is estimated that 2 billion individuals have been infected with HBV and 350 million are the chronic carriers. In the data of World Health Organization (WHO) in 1997, the rate of chronic HBsAg carriers in Asian is higher compared with other continents, HBsAg seroprevalence in the north and central Asian countries ranged between $10 \%$ and $12 \%$ and in Southeast Asia it ranged between $1 \%$ and $10 \%$ with a total number of 130 million. But in the United States and northern European countries, it is under $0.5 \%$ [1]. In the Chinese epidemiological investigation of $\mathrm{HBV}$ in 2006, the rate of chronic HBsAg carriers was $7.18 \%$, and it is about 93 million patients with HBV chronic infection [2]. With the development of human genome research, there is strong evidence in $\mathrm{HBV}$ infection that host genetic factors play

\footnotetext{
* Correspondence: bysyin@163.com

Department of Infectious Disease, Peking University Third Hospital, 100191 Beijing, China
}

a major role in determining the outcome of infection. The incidence of hepatitis B in Asian is high, so there may be genetic susceptibility in Asian people. The researchers have done much study on this issue in recent years, and Interleukin 28B (IL28B) has been a hot research topic on hepatitis virus, especially hepatic C virus. IL28B plays an important role in the outcome of hepatic $\mathrm{C}$ virus by genome-wide association studies (GWAS) [3] and it could inhibit hepatitis B and C virus replication [4]. HBV and $\mathrm{HCV}$ share some similarities in pathogenesis, natural history and acquired immune responses, but the relationship between ILB28 and HBV is still unclear. Rs12979860 and rs8099917 were widely studied in the previous research, so in this study, we performed a meta-analysis on single nucleotide polymorphisms (SNPs) of IL28B (rs12979860 and rs8099917) to evaluate the relationships between the genetic loci and HBV in Asian population, especially in Chinese population. 


\section{Methods}

Identification of eligible studies

We searched the databases including PubMed, MEDLINE, EMBASE, China National Knowledge infrastructure (CNKI) and WanFang database for case-control studies on IL28B published in Asian population up to March, 2015. The search terms included IL28B and Asian and HBV. Then we selected the papers included IL28B-rs12979860 and rs8099917 (Figure 1, Tables 1 and 2).

\section{The criteria of articles included and excluded in the meta-analysis}

The articles included in the study should meet the following criteria: (1) the subjects were the Asian population; (2) the study was a case-control study including the HBV group and the control group. All patients with HBV infection were selected for the study including chronic hepatitis $\mathrm{B}$ patients, $\mathrm{HBV}$-related $\mathrm{HCC}$ patients and inactive $\mathrm{HBsAg}$ carriers; (3) The articles included should be full text in

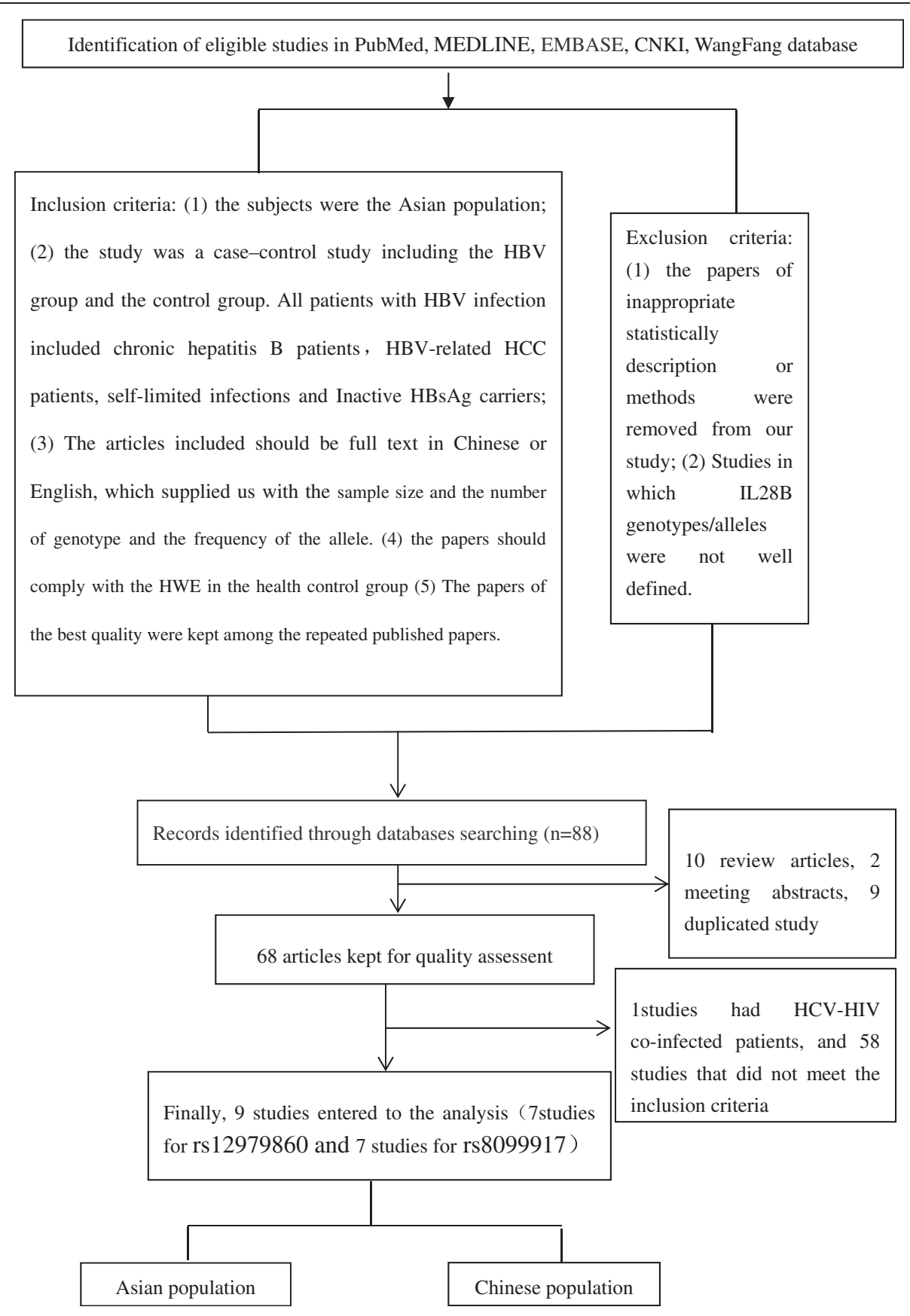

Figure 1 The flowchart of the meta-analysis. 
Table 1 Characteristics of the papers included in the meta-analysis and allele frequency of IL28B rs12979860 (C-T)

\begin{tabular}{|c|c|c|c|c|c|c|c|}
\hline \multirow[t]{2}{*}{ SNP } & \multirow[t]{2}{*}{ Area } & \multirow[t]{2}{*}{ Author } & \multirow[t]{2}{*}{ Year } & \multicolumn{2}{|c|}{$\begin{array}{l}\text { allele frequency } \\
\text { of HBV infection } \\
(N=1,052)\end{array}$} & \multicolumn{2}{|c|}{$\begin{array}{l}\text { allele frequency of } \\
\text { control group } \\
(\mathrm{N}=2,823)\end{array}$} \\
\hline & & & & $C$ & $\mathbf{T}$ & $C$ & $\mathbf{T}$ \\
\hline \multirow[t]{7}{*}{ rs12979860 } & China & Shi et al. [16] & 2011 & 153 & 11 & 34 & 0 \\
\hline & China & Li et al. [10] & 2011 & 760 & 104 & 382 & 24 \\
\hline & China & Chen et al. [17] & 2012 & 2238 & 172 & 455 & 33 \\
\hline & China & Ren et al. [12] & 2012 & 236 & 46 & 45 & 2 \\
\hline & China & Lv et al. [18] & 2012 & 488 & 36 & 525 & 29 \\
\hline & Korea & Kim et al. [15] & 2013 & 707 & 41 & 185 & 15 \\
\hline & Thai & KimKong et al. [19] & 2015 & 398 & 24 & 304 & 24 \\
\hline Sum & & & & 4,980 & 434 & 1,930 & 127 \\
\hline
\end{tabular}

Chinese or English, which supplied us with the sample size and the number of genotype and the frequency of the allele. (4) The papers should comply with the HardyWeinberg equilibrium (HWE) in health control group (5) Paper of the best quality was remained among the repeated published papers. (6) The papers should have been performed with the ethical approval and patient consent.

The criteria of articles excluded from the study were: (1) The papers of inappropriate statistically description or methods were removed; (2) Studies in which IL28B genotypes/alleles were not well defined (Figure 1).

\section{Data extraction and analysis}

We extracted data from the papers included (ethnicity, genotypic distribution and allelic frequency) and performed meta-analysis by STATA, version11.0 under an additive genetic model. (Tables 2 and 3) The heterogeneity was assessed by Cochran $\mathrm{Q}$ test $(\mathrm{P}<0.1$ was considered to be significant). The heterogeneity was classed by $\mathrm{I}^{2}$ statistical test $\left(\mathrm{I}^{2}<25 \%\right.$ : low heterogeneity; $\mathrm{I}^{2}=25-50 \%$ : moderate heterogeneity; $\mathrm{I}^{2}=50-75 \%$ : high heterogeneity; $\mathrm{I}^{2}>75 \%$ : extreme heterogeneity value) [5]. If $\mathrm{P}>0.1$ in Cochran $\mathrm{Q}$ test, the pooled ORs and 95\% CIs were calculated in fixed effect model; otherwise in random effect model.
Publication bias was evaluated by Begg's test ( $\mathrm{P}<0.05$ was considered to be significant).

\section{Results}

Results of meta-analysis of rs12979860 in Asian population In the meta-analysis of rs12979860 in Asian population, the pooled sample included 2,823 subjects with HBV infection and 1,052 control subjects from 7 studies in Asian population. There was high heterogeneity among studies by Cochran $\mathrm{Q}$ test $\left(\mathrm{P}<0.1, \mathrm{I}^{2}=63.2 \%\right)$ and a random effect model was performed under an additive model. The pooled OR of risk allele $\mathrm{T}$ was $0.79(95 \% \mathrm{CI}, 0.53-1.18$; $\mathrm{P}=$ $0.25)$. No publication bias was found in the meta-analysis (corrected $\mathrm{Z}=0.30$ and corrected $\mathrm{p}=0.76$ ) (Figure 2A, Table 3).

\section{Results of meta-analysis of rs 12979860 in Chinese population}

In the meta-analysis of rs12979860 in Chinese population, the pooled sample included 2,238 subjects with HBV infection and 788 control subjects from 5 studies in Chinese population. There was no heterogeneity among studies by Cochran $\mathrm{Q}$ test $\left(\mathrm{P}<0.1, \mathrm{I}^{2}=54.3 \%\right)$ and a random effect

Table 2 Characteristics of the papers included in the meta-analysis and allele frequency of IL28B rs rs8099917 (T-G)

\begin{tabular}{|c|c|c|c|c|c|c|c|}
\hline \multirow[t]{2}{*}{ SNP } & \multirow[t]{2}{*}{ Area } & \multirow[t]{2}{*}{ Author } & \multirow[t]{2}{*}{ Year } & \multicolumn{2}{|c|}{$\begin{array}{l}\text { allele frequency } \\
\text { of HBV infection } \\
(\mathrm{N}=3,613)\end{array}$} & \multicolumn{2}{|c|}{$\begin{array}{l}\text { allele frequency } \\
\text { of control group } \\
(\mathrm{N}=1,409)\end{array}$} \\
\hline & & & & $\mathrm{T}$ & G & $\mathrm{T}$ & G \\
\hline \multirow[t]{7}{*}{ rs8099917 } & China & Li et al. [10] & 2011 & 764 & 48 & 385 & 21 \\
\hline & China & Chen et al. [17] & 2012 & 2276 & 134 & 461 & 27 \\
\hline & China & Ren et al. [12] & 2012 & 248 & 34 & 45 & 2 \\
\hline & Korea & Kim et al. [15] & 2013 & 852 & 38 & 196 & 16 \\
\hline & Thai & Kimkong et al. [19] & 2015 & 402 & 20 & 303 & 25 \\
\hline & China & Jiao et al. [11] & 2011 & 643 & 41 & 276 & 12 \\
\hline & China & Ma et al. [20] & 2012 & 1494 & 90 & 947 & 67 \\
\hline Sum & & & & 6,679 & 405 & 2,989 & 170 \\
\hline
\end{tabular}


Table 3 The result of meta-analysis of rs12979680 and rs8099917

\begin{tabular}{|c|c|c|c|c|c|c|c|c|}
\hline \multirow[t]{2}{*}{ SNPs } & \multirow[t]{2}{*}{ Ethnicity } & \multirow[t]{2}{*}{ Model } & \multirow[t]{2}{*}{ Pooled OR $(95 \% \mathrm{Cl})$} & \multirow[t]{2}{*}{$\mathbf{P}$} & \multicolumn{2}{|c|}{ Heterogeneity } & \multicolumn{2}{|c|}{ Publication bias } \\
\hline & & & & & $I^{2}$ & $\mathbf{P}$ & z & $\mathbf{P}$ \\
\hline rs12979680 & Asian & Random & $0.79(0.53-1.18)$ & 0.25 & $63.2 \%$ & $<0.1$ & 0.30 & 0.76 \\
\hline rs12979680 & Chinese & Random & $1.62(1.04-2.51)$ & 0.033 & $54.3 \%$ & $<0.1$ & 0.73 & 0.46 \\
\hline rs8099917 & Asian & Fixed & $1.05(0.93-1.19)$ & 0.44 & $43.3 \%$ & $>0.1$ & 0.9 & 0.37 \\
\hline rs8099917 & Chinese & Fixed & $0.90(0.84-1.81)$ & 0.726 & $15.6 \%$ & $>0.1$ & 1.71 & 0.09 \\
\hline
\end{tabular}

model was performed under an additive model. The pooled OR of risk allele $\mathrm{T}$ was 1.62 (95\% CI, 1.04-2.51; $\mathrm{P}=$ $0.033)$. No publication bias was found in the meta-analysis (corrected $\mathrm{Z}=0.73$ and corrected $\mathrm{p}=0.46$ ) (Figure 2B, Table 3).

Results of meta-analysis of rs8099917 in Asian population In the meta-analysis of rs8099917, the pooled sample included 3,613 subjects with HBV infection and 1,409 control subjects from 7 studies in Asian population. There was no heterogeneity among studies by Cochran $\mathrm{Q}$ test $\left(\mathrm{P}>0.1, \mathrm{I}^{2}=43.3 \%\right)$ and a fixed effect model was performed under an additive model. The pooled OR of risk allele $\mathrm{T}$ was 1.05 (95\% CI, 0.93-1.19; $\mathrm{P}=0.44$ ). No publication bias was found in the meta-analysis (corrected $\mathrm{Z}=0.9$ and corrected $\mathrm{p}=0.37$ ) (Figure 3A, Table 3).

Results of meta-analysis of rs8099917 in Chinese population In the meta-analysis of rs8099917, the pooled sample included 3,048 subjects with HBV infection and 1,145 control subject from 5 studies in Chinese population. There was no heterogeneity among studies by Cochran $\mathrm{Q}$ test $\left(\mathrm{P}>0.1, \mathrm{I}^{2}=15.6 \%\right)$ and a fixed effect model was performed under an additive model. The pooled OR of risk allele $\mathrm{T}$ was 0.97 (95\% $\mathrm{CI}, 0.84-1.23$; $\mathrm{P}=0.726$ ). No publication bias was found in the meta-analysis (corrected $\mathrm{Z}=1.71$ and corrected $\mathrm{p}=0.09$ ) (Figure 3B, Table 3).

\section{Discussion}

IL-28B belongs to the type III IFN family, and encodes a cytokine related to type I interferons and the IL-10 family. IL-28B, IL28A and IL29 are three closely related cytokine genes located on 19q13. Expression of the three genes can be induced by viral infection. Several GWAS studies on the SNP loci affecting antiviral therapy of $\mathrm{HCV}$, and multiple SNPs on the IL28B gene were associated with sustained virological response (SVR). The link was strongest among rsl2979860 $3 \mathrm{~kb}$ upstream of IL28B gene and rs8099917 $8 \mathrm{~kb}$ upstream of the IL28B gene. Rsl2979860 is significantly associated with the response to Peg-IFN and ribavirin for patients with chronic HCV infection. In a study to investigate the association between rs12979860 and the end-of-treatment response (ETR) or SVR in the Chinese Han population, genotype CC was the main genotype (87.64\%). The patients with genotype CC had higher rates of ETR and SVR than the patients with $\mathrm{CT}$ or TT genotype [6]. There are differences in response to treatment between patients of European ancestry and African-Americans. In patients of European ancestry, the CC genotype is associated with a twofold greater rate of SVR than the TT genotype, threefold in AfricanAmerican and twofold in Hispanic population [7]. CC genotype of rsl2979860 strongly enhances resolution of $\mathrm{HCV}$ infection among individuals of both European and African ancestry [8]. The studies above suggest that the effect of rsl2979860 differs in races of diverse genetic background.

In Chinese patients with dual chronic infection with hepatitis B and C viruses, rs8099917 TG genotype could increase the risk of null virological response (NVR) $(\mathrm{OR}=2.37, \mathrm{P}=0.017)$, and the GG genotype had a further increased risk of NVR $(\mathrm{OR}=4.23, \mathrm{P}=0.027)$. The rs12979860 allele was associated with treatment failure (CT/TT vs. CC: OR =2.04, P =0.037). IL28B rs8099917 $G$ variant leads to higher risk of NVR $(P=0.009)$ in HCV genotype 1 [8]. In GWAS to NVR in the treatment of patients with HCV genotype 1 of Japanese population, rs8099917 was strongly associated with NVR and SVR [9].

The relationship between IL28B and HCV is widely studied, but the association study between IL28B and HBV infection is much less and the results were inconsistent in previous studies. In two studies of rs12979680 on infection of hepatitis B virus in Chinese people, there was no association between rs12979680 and HBV infection $[10,11]$. In another Chinese study, both $C$ allele and CC genotype were protective, which indicated that the rs12979860 TC polymorphism is associated with the carcinogenic process of chronic hepatitis $\mathrm{B}$ and HBVrelated HCC [12]. In a meta-analysis of rs12979680, no significant correlation with $\mathrm{HBV}$ infection outcomes was found, and the pooled OR was 0.42 (95\% CI, 0.11-1.51; P = $0.184, \mathrm{I}^{2}=75.9 \%$ ) in Asian population [13]. But in our study, T allele of rs12979680 can increase the risk of HBV infection in Chinese population but not Asian population under an additive genetic model, the pooled OR (95\% CIs) were 1.62 (1.04-2.51). Compared with the previous metaanalysis of rs12979680 (the included three papers was updated in July 2013) [14], our study contains more papers and more sample size. In the seven papers of our metaanalysis, there are five studies on Chinese population, one 


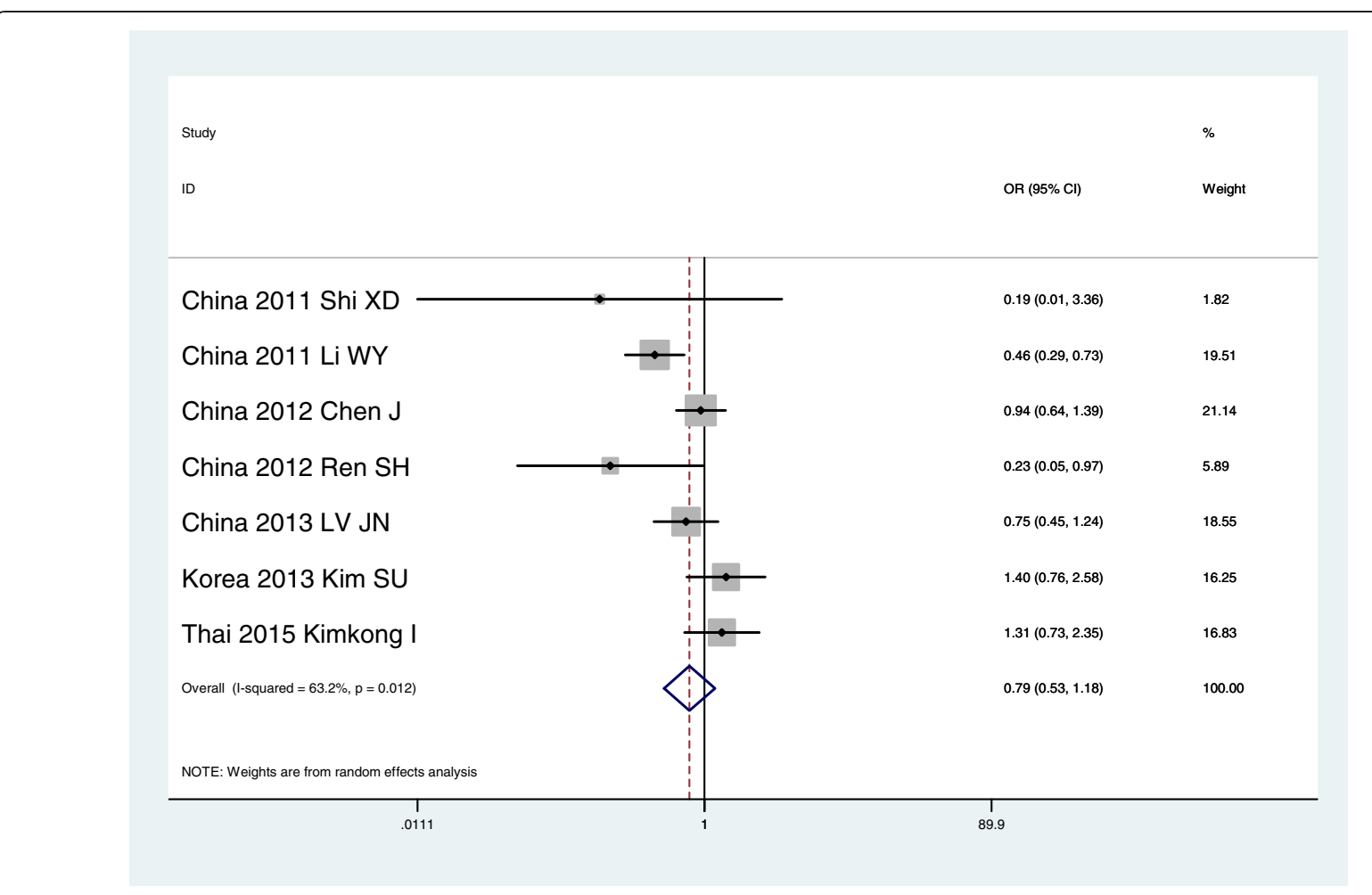

A

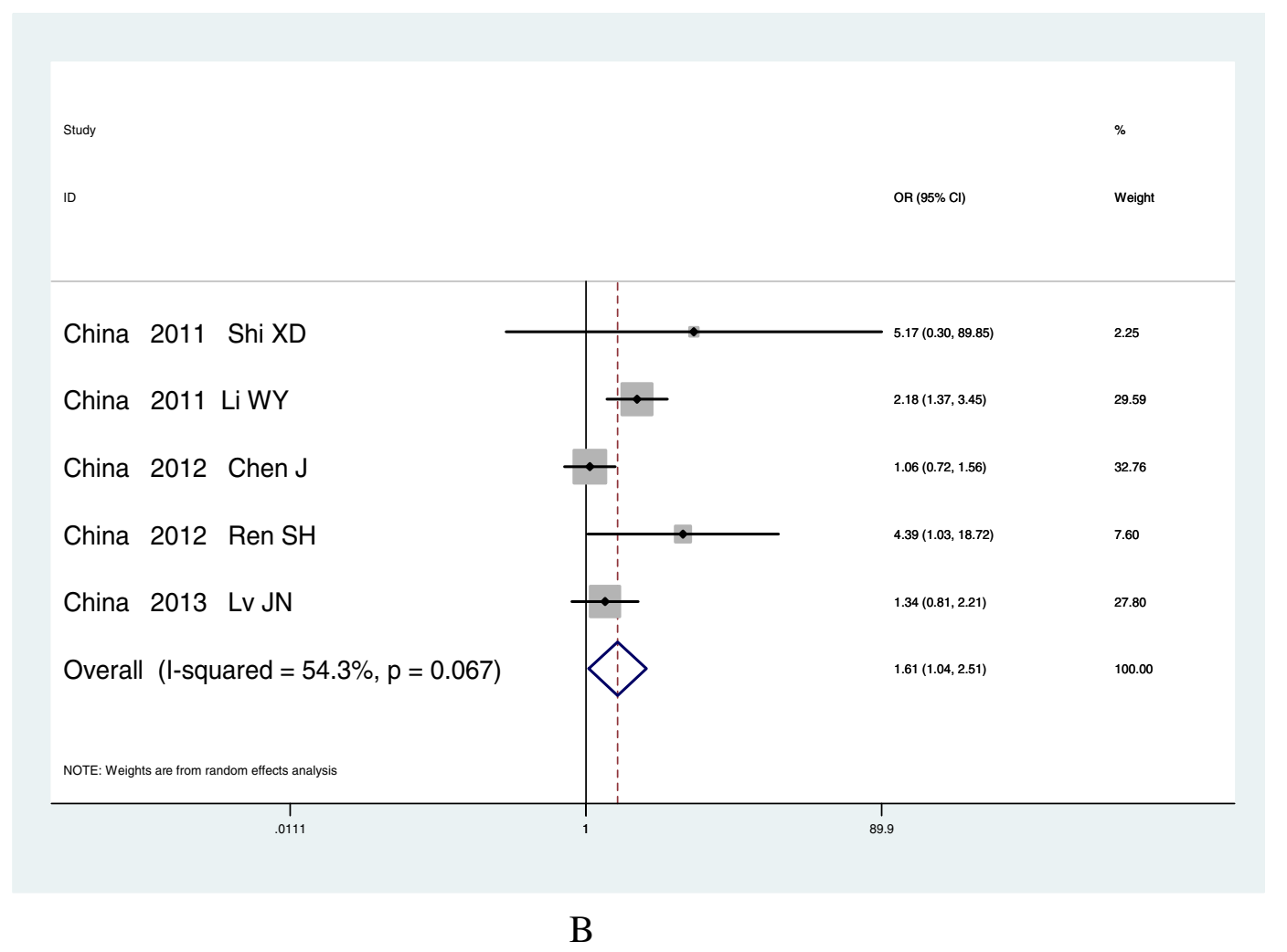

Figure 2 Meta-analysis results of rs12979680(C-T) Panel A. Meta-analysis results of rs12979680(C-T) in Asian population. Panel B. Meta-analysis results of rs12979680(C-T) in Chinese population. 


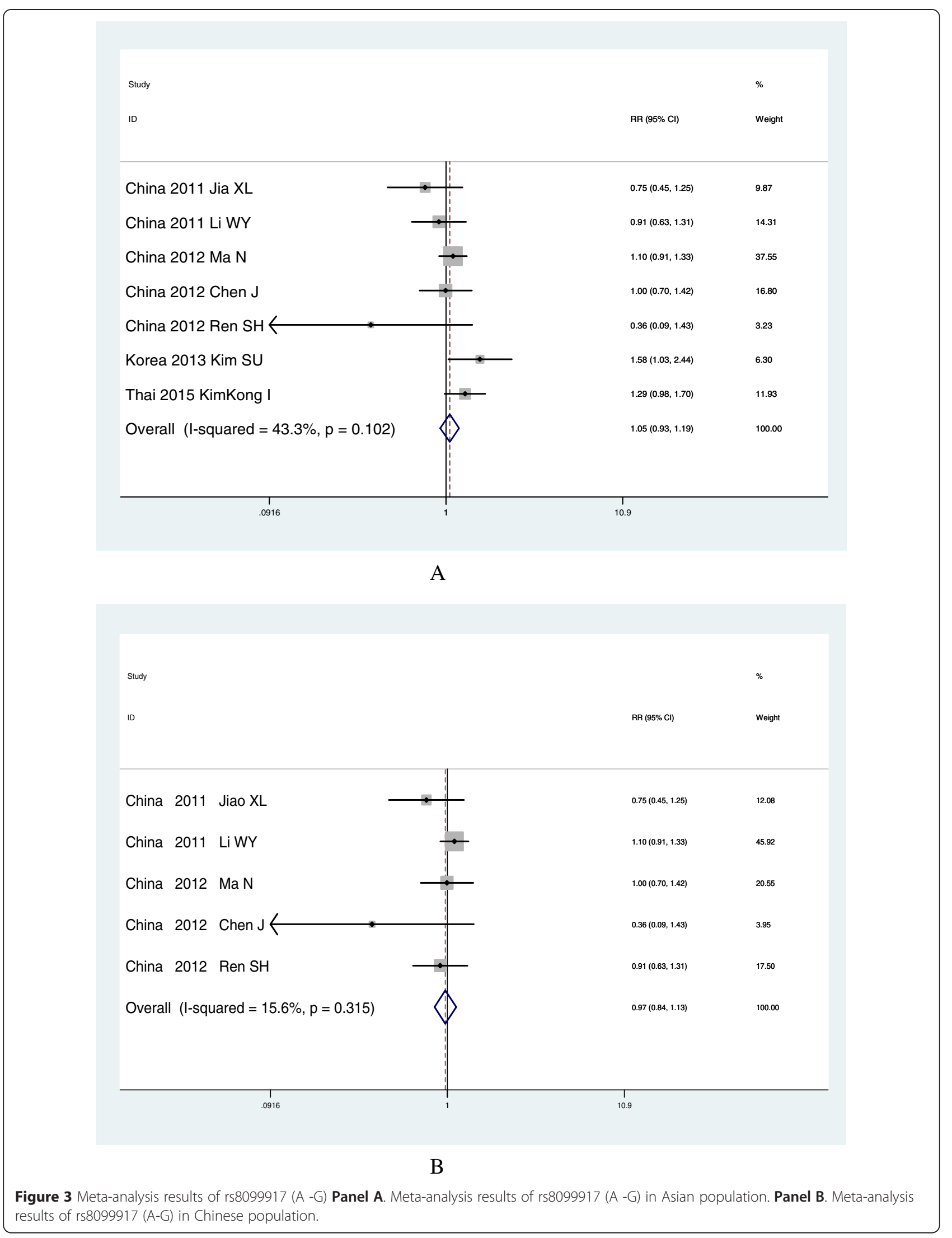


on Korea and one on Thai population, the frequency of $\mathrm{T}$ allele is $6.7 \sim 12.8 \%$ in Chinese population which is higher compared with $5.5 \%$ in Korea population and $6.4 \%$ in Thai population. The difference in the frequency of $\mathrm{T}$ allele in China, Korea and Thai may explain the inconsistent result in the meta-analysis on the Chinese population and the Asian population. However, the papers included in the meta-analysis are not enough and the result deserves more research to testify.

In our meta-analysis of rs8099917, there is no association between rs8099917 and susceptibility of HBV in both Chinese population and the Asian population. Jiao et al. demonstrate that rs8099917 is not associated with the HBV infection [11], which is consistent with our result. In another research, rs8099917 is strongly associated with glutamic-pyruvic transaminase (ALT) level and HBV viral load [10] IL28B rs8099917 AA genotype (AA vs $\mathrm{AC}+\mathrm{CC}$ : odds ratio $(\mathrm{OR})=0.63$ ) was associated with a decreased risk of HCC [13]. In a Korea study, rs8099917 is significantly associated with the outcomes of HBV infection [15]. The result deserves more research to testify.

\section{Study limitations}

There are several limitations that should be stated. First, the frequency of the allele is not classified by the hepatitis $B$ virus genotypes which are different in different countries. Second, only seven papers were included in the meta-analysis, and so the association between IL28B (rs12979680 and rs8099917) and infection susceptibility of HBV in this meta-analysis deserves further replication.

\section{Conclusions}

In summary, our study demonstrated that $\mathrm{T}$ allele of rs12979680 can increase the risk of HBV infection in Chinese population but not Asian population under an additive genetic model. There is no association between rs8099917 HBV infection in Chinese population and Asian population.

\footnotetext{
Abbreviations

HBV: Hepatitis B virus; WHO: World Health Organization; IL28B: Interleukin 28B; GWAS: Genome-wide association studies; SNPs: Single nucleotide polymorphisms; HWE: Hardy-Weinberg equilibrium; OR: Odds ratios; CNKI: China National Knowledge infrastructure; SVR: Sustained virological response; ETR: End of treatment response; NVR: Null virological response; ALT: Glutamic-pyruvic transaminase.
}

\section{Competing interests}

The authors declare that they have no competing interests.

Authors' contributions

$C J$ and $X J$ designed the study, CJ and LXG collected the papers and conducted statistical of the data. CJ and WW wrote the manuscript and performed the English editing. All the authors read and approved the final manuscript.

\section{Acknowledgements}

We thank Dr. Jia Ying, Dr. Li Lu, Dr. Lin Fei, Dr. Liang Jingjin and other members of our department for their assistance in the study.

Received: 5 January 2015 Accepted: 24 April 2015

Published online: 12 May 2015

\section{References}

1. Custer B, Sullivan SD, Hazlet TK, lloeje U, Veenstra DL, Kowdley KV. Global epidemiology of hepatitis B virus. J Clin Gastroenterol. 2004;38(10 Suppl 3):S158-68.

2. Chinese Society of Hepatology and Chinese Society of Infectious Diseases, Chinese Medical Association. The guideline of prevention and treatment for chronic hepatitis B (2010 version). Chin J Epidemiol. 2011;32(4):405-15.

3. Tanaka Y, Nishida N, Sugiyama M, Kurosaki M, Matsuura K, Sakamoto N, et al. Genome-wide association of IL28B with response to pegylated interferon-alpha and ribavirin therapy for chronic hepatitis C. Nat Genet. 2009;41(10):1105-9.

4. Robek MD, Boyd BS, Chisari FV. Lambda interferon inhibits hepatitis B and C virus replication. J Virol. 2005;79(6):3851-4.

5. Higgins PT, Thompson GS. Quantifying heterogeneity in a meta-analysis. Stat Med. 2002;21:1539-58.

6. Liao XW, Ling Y, Li XH, Han Y, Zhang SY, Gu LL, et al. Association of genetic variation in IL28B with hepatitis C treatment-induced viral clearance in the Chinese Han population. Antivir Ther. 2011;16(2):141-7.

7. Ge D, Fellay J, Thompson AJ, Simon JS, Shianna KV, Urban TJ, et al. Genetic variation in IL28B predicts hepatitis $C$ treatment-induced viral clearance. Nature. 2009;461(7262):399-401.

8. Thomas DL, Thio CL, Martin MP, Qi Y, Ge D, O'Huigin C, et al. Genetic variation in IL28B and spontaneous clearance of hepatitis C virus. Nature. 2009;461 (7265):798-801.

9. Guo X, Yang G, Yuan J, Ruan P, Zhang M, Chen X, et al. Genetic variation in interleukin $28 \mathrm{~B}$ and response to antiviral therapy in patients withdual chronic infection with hepatitis B and C viruses. PLoS One. 2013;8(10):e77911.

10. Li WY, Jiang YF, Jin QL, Shi $\sqcup$, Gao YH, Pan Y, et al. Expression and gene polymorphisms of interleukin $28 \mathrm{~B}$ and hepatitis $\mathrm{B}$ virus infection in a Chinese Han population. Liver Int. 2011;31(8):1118-26.

11. Jiao $X L$, Gao $Y T$, Jing L, Liu T, Shi $W X$, Guo H, et al. Studies on the relationship between polymorphism of IL-28B rs8099917 and the outcome of HBV infection. Chin J Epidemiol. 2011;32(11):1143-7.

12. Ren $S H$, Lu JF, Du XF, Huang YX, Ma LN, Huo HL, et al. Genetic variation in IL28B is associated with the development of hepatitis B-related hepatocellular carcinoma. Cancer Immunol Immunother. 2012;61:1433-9.

13. Xia P, Zhou M, Dong DS, Xing YN, Bai Y. Association of polymorphisms in interleukin-18 and interleukin-28B genes with outcomes of hepatitis B virus infections: a meta-analysis. Tumor Biol. 2014;35:1129-37.

14. Tang SD, Yue M, Wang JJ, Zhang Y, Yu RB, Su J, et al. Associations of IFN-y rs2430561 T/A, IL28B rs $12979860 \mathrm{C} / \mathrm{T}$ and ERa rs2077647 T/C polymorphisms with outcomes of hepatitis B virus infection: a meta-analysis. J Biomed Res. 2014;28(6):484-93.

15. Kim SU, Song KJ, Chang YH, Shin EC, Park JY, Kim DY, et al. Association between IL28B polymorphisms and spontaneous clearance of hepatitis B virus infection. PLoS One. 2013;8(7):e69166.

16. Shi XD. Genetic variation and expression of IL28B are associated with HCV and HBV infection in Chinese population. Jilin: Jilin University; 2011.

17. Chen J, Wang LL, Li Y, Cai B, Fu Y, Liao Y, et al. Association analysis between SNPs in IL-28B gene and the progress of hepatitis B infection in Han Chinese. PLoS One. 2012;7(12):e50787.

18. LV JN. Study of the association of interleukin-28B gene polymorphism with prognosis of disease and response to antiviral treatment with PEG-IFN-2ain hepatitis C virus/hepatitis B virus infected patients. Jilin: Jilin University; 2013.

19. Kimkong I, Chankaew J, Kunanopparat A, Hirankarn N, Tangkijvanich P. Gene polymorphisms of interleukin $28 \mathrm{~B}$ and the risk to chronic hepatitis $\mathrm{B}$ virus infection in Thai. Tissue Antigens. 2015;85(3):177-81.

20. Ma N. Impact of candidate genetic polymorphisms on the infection and infection outcomes of hepatitis B virus. Hebei: Heibei Medical University; 2012. 